\title{
Splitting Tensile Strength of Lightweight Foamed Concrete with Polypropylene Fiber
}

\author{
Freccy Raupit", Anis Saggaff*, Cher Siang Tan ${ }^{\$}$, Yee Ling Lee ${ }^{\&}$, Mahmood Md Tahir ${ }^{\%}$ \\ ${ }^{\#}$ Faculty of Civil Engineering, Universiti Teknologi Malaysia, 81310 UTM Johor, Malaysia, \\ E-mail:freccyrupert@gmail.com \\ ${ }^{*}$ Faculty of Engineering, Universitas Srivijaya, Palembang, Indonesia, \\ E-mail:anissaggaff@yahoo.com
}

${ }^{\$}$ Forensic Engineering Centre, Universiti Teknologi Malaysia, 81310 UTM Johor, Malaysia, E-mail: tcsiang@utm.my (corresponding author)

${ }^{\&}$ Lee Kong Chian Faculty of Engineering and Science, Universiti Tunku Abdul Rahman, 43000 Selangor, Malaysia, E-mail:yllee@utar.edu.my

\author{
${ }^{\%}$ Construction Research Centre, Institute for Smart Infrastructure and Innvative Construction, Universiti Teknologi Malaysia, 81310 UTM \\ Johor, Malaysia, \\ E-mail:mahmoodtahir@utm.my
}

\begin{abstract}
This paper presents the design mix of foamed concrete and split tensile strength of lightweight foamed concrete with the addition of polypropylene fiber. The design mix of the foamed concrete was targeted to achieve a density of $1500 \mathrm{~kg} / \mathrm{m}^{3}$. Six different water-cement ratios (w/c) range from 0.30 to 0.40 were taken into consideration. Three different group of LFC with $0 \%$ PP, $0.25 \%$ PP and $0.40 \%$ PP are prepared. The optimum w/c was determined by comparing the compressive test result of different percentage polypropylene fiber. By using the LFC with optimum w/c ratio and designated amount of PP of 3:1 c/s ratios, the concrete specimens were tested with splitting tensile test to determine the effects of PP to the tensile strength of the lightweight foamed concrete. From the result, it is found that by using $2: 1 \mathrm{c} / \mathrm{s}$ ratio, the optimum w/c of mix with $0 \% \mathrm{PP}, 0.25 \% \mathrm{PP}$ and $0.40 \% \mathrm{PP}$ are $0.36,0.34$ and 0.32 respectively, while for c/s equals to $3: 1$, the optimum w/c are $0.34,0.32$ and 0.32 respectively. From the splitting tensile result, under a controlled density of $1500 \pm 50 \mathrm{~kg} / \mathrm{m}^{3}$, the tensile strength range of $0.991-2.138 \mathrm{MPa}$ was observed. From the result, it can be concluded that the addition of polypropylene fiber to the lightweight foamed concrete does affect the tensile strength of the foamed concrete. However the further addition of PP will not cause any positive and significant effect to the tensile strength of lightweight foamed concrete.
\end{abstract}

Keywords - lightweight foamed concrete; polypropylene fiber; compressive strength; splitting tensile strength; cement-sand ratio; water-cement ratio

\section{INTRODUCTION}

Concrete is a construction material that had been widely used for many centuries. It is obtained by mixing the binder, normally refer to Portland cement, coarse and fine aggregates and water with certainly designed proportion. Conventional normal weight concrete is dense, hard, strong and durable construction material. However, the density of conventional normal weight concrete is in the range of 2300 $\mathrm{kg} / \mathrm{m}^{3}$ to $2700 \mathrm{~kg} / \mathrm{m}^{3}$. This heavy self-weight may be inconvenient for construction that required a large volume of concrete casting over long span structures, or precast reinforced concrete members that need for transportation to the construction site. With the aim towards lighter and sustainable construction, lightweight foamed concrete is introduced as an innovative product, which provides light density ranging from $1000 \mathrm{~kg} / \mathrm{m}^{3}$ to $1600 \mathrm{~kg} / \mathrm{m}^{3}$, better fire protection, thermal and sound insulation, etc.

Lightweight concrete is concrete which intentionally made lighter than the conventional concrete. By practical experience in industry, the building rate is faster with the usage of lightweight concrete than the traditional materials because the total materials to be handled are reduced with a consequent increase in productivity [1]. The lightweight concrete material can be divided into three groups i.e. no- 
fines concrete, lightweight aggregate concrete and aerated / foamed concrete. No-fines concrete composes cement and a coarse aggregate of size $9-19 \mathrm{~mm}$; lightweight aggregate concrete is produced by using a lightweight aggregate of low apparent specific gravity. Aerated or foamed concrete is concrete with entrapped air.

Lightweight foamed concrete (LFC) is cement-based slurry which stable and homogenous foam. It is mechanically blended, either by mixing or by injecting. It has been used around the world since 1920 but with the limited application [2]. Foamed concrete is high flowability, low self-weight, minimal consumption of aggregate and excellent thermal insulation properties [3]. The development of lightweight foamed concrete started when a full -scale trial of foamed concrete usage for reinstatement undertaken in the UK in 1987. This success led to the other applications of lightweight foamed concrete [4]. Kearsley [5] stated that the compressive strength of the concrete decreases exponentially with the reduction of its density. According to Valore [6] the compressive strength influenced by the size and shape of the specimen, method of pore formation, direction load applied, age, water content, ingredients used and the method of curing applied. The mechanical properties of lightweight foamed concrete especially in compressive strength is depend on many factors such as cement to sand ratios $(\mathrm{c} / \mathrm{s})$, curing duration and water to cement ratios $(\mathrm{w} / \mathrm{c})$. In foamed concrete, according to Mindness [7], small changes in the water-cement ratio do not influence the strength as much as in normal concrete. This because foamed concrete is characterized by its plastic density and the voids is an important determinant of the strength.

Several types of fiber have been used to study the properties and characteristics of foamed concrete e.g. synthetic and natural fibers consisting AR-glass, polypropylene fiber, steel, kenaf and oil palm fiber. The ARglass also found to be the most effective in controlling the drying shrinkage [8]. However, Jones [9] found that conventional and glass fiber were too rigid and easy settle in a material with relatively thin walls of solid mortar between the bubbles. Polypropylene fiber is a micro synthetic. It has some unique properties that make them suitable for reinforcement in concrete. The fibers have a low density, are chemically inert and non-corrosive [10]. This fiber has been widely used as a reinforcement of cementitious materials to improve the toughness and energy absorption. It has been stated that the presence of PP fiber in cement paste results in the formation of a water film at the interface between fiber and matrix called wall effect. The great mobility of calcium ions in water environment causes the portlandite macrocrystal can easily grow and make the transition zone more pores [11].

The strength of lightweight foamed concrete is normally ranged from $5 \mathrm{MPa}$ to $18 \mathrm{MPa}$. The foamed concrete will not be considered as a structural material unless the achieved strength is at least $25 \mathrm{~N} / \mathrm{mm}^{2}(25 \mathrm{MPa})$ which the normal grade of concrete use for structural materials, in both economic and environmental manner. However, since the needs for lighter, sustainable and economical construction materials are highly demanded, this leads the material to a further study and investigations to improve its characteristics especially in terms of engineering properties. Furthermore, foaming method reported as the most economical and controllable pore-forming process, as there are no chemical reactions involved. The design strength of foamed concrete normally decreases as the density decrease. To satisfy the desired strength, fly ash is used to replace the Portland cement and fine aggregate. This replacement causes high drying shrinkage, low tensile strength and low elastic modulus [9]. To improve this performance, Portland cement is used with an addition of fiber to the foamed concrete. There are few types of fiber can be taken into consideration such as steel fiber, kenaf, glass, and polypropylene fiber. Out of these fibers, polypropylene fiber found to be the most flexible fiber to be utilized.

The objectives of this study are to produce lightweight foamed concrete (LFC) with $1500 \mathrm{~kg} / \mathrm{m}^{3}$ density using 2:1 cement-sand ratios, to obtain optimum water cement ratios for various percentage of Polypropylene fiber in lightweight foamed concrete with cement to sand ratios of $2: 1$, and to study the effects of Polypropylene Fiber (PP) on engineering properties lightweight foamed concrete. the lightweight foamed concrete (LFC) was produced to investigate the effects of Polypropylene Fiber (PP) on its engineering properties in terms of splitting and tensile strength of the LFC. The targeted density of the LFC is $1500 \mathrm{~kg} / \mathrm{m} 3$ with the tolerance of $\pm 50 \mathrm{~kg} / \mathrm{m}^{3}$. The optimal mixes for the foamed concrete include LFC with $0 \%, 0.25 \%$, and $0.40 \%$ of PP. All the mixes will be added with $1 \%$ of cement weight of Superplasticizer (SP) Polycarboxylic either to enhance the workability of the concrete and at the same time reducing the water content needed to achieve higher strength.

Since the cement-sand ratio is one of the parameters affecting compressive strength of concrete, the parameter is fixed to $2: 1$ while the density is controlled to $1500 \mathrm{~kg} / \mathrm{m}^{3}$. The types of sand use also the same and particle size controlled to less than $0.6 \mathrm{~mm}$. In the trial mix of $2: 1$ cement-sand ratio, six different water-cement ratio $(\mathrm{w} / \mathrm{c})$ ranging from 0.30 to $0.40(0.30,0.32,0.34,0.36,0.38,0.40)$ for each proportion with different percentage of PP were prepared. This is to determine the optimum w/c ratio for the each different percentage of the PP. Three samples prepared for each different w/c ratio. During the trial mix, two testing are carried out, namely flow table test and compressive test to determine the workability and consistency of fresh concrete and the optimum w/c respectively. Flow table test carried out prior to the casting of each trial mix while the compressive test underwent for compressive strength after 7 days of curing. The optimum w/c ratios for each mix were determined by screening the results of the trial mixes. By using the gained w/c ratios, other specimens for each different percentage of PP were prepared. Each specimen should include cylinders splitting tensile test. The testing repeated for 7 days, 28 days and 90 days curing. The engineering properties in term of splitting tensile strength of lightweight concrete with $0 \%, 0.25 \%$ and $0.40 \%$ PP using a cement-sand ratio of 2:1 were studied and discussed.

\section{MATERIAL AND METHOD}

\section{A. Material Preparation}

Ordinary Portland Cement (OPC) was used throughout the study. The OPC used complied with Type I Portland 
cement in accordance with ASTM. The sand was taken from the bulk condition which was exposed directly to the natural weathering. It was oven dried at a temperature of $150{ }^{\circ} \mathrm{C} \pm$ $5^{\circ} \mathrm{C}$ for 24 hours before undergoing the sieve analysis. In order to control the size of the sand particles, the sand was sieve by $100 \%$ pass through $0.60 \mathrm{~mm}$ sieve size. The quantity of sand was calculated based on the cement-sand ratio $2: 1$. Silica fume is added by $10 \%$ of the cement weight to the mixture to improve the concrete properties.

The dimension of the Polypropylene fiber used is $12 \mathrm{~mm}$ of length, $22 \mathrm{~m}$ of diameter. In this study $0.25 \%$ and $0.40 \%$ $\mathrm{PP}$, which is equivalent to $0.25 \mathrm{~kg} / \mathrm{m}^{3}$ and $0.40 \mathrm{~kg} / \mathrm{m}^{3}$ respectively added to the sample. The polypropylene fiber is to enhance the strength of the foamed concrete.

The foam is locally manufactured synthetic-based foaming agent. The foaming agent was diluted with water with the ratio of 1:30. The foaming agent is compressed at a pressure of 5.0 bar to produce a stable bubble to control the density of the foam concrete. The amount of foam added to the mortar mix is depending on the controlled density.

\section{B. Test Specimen}

Three types of the trial mix for LFC were investigated. The cement-sand ratio was fixed at 2:1, while $0 \%, 0.25 \%$ and $0.40 \%$ PP fiber were added for each type of trial mix. Each trial mix were tested in accordance with the watercement $(\mathrm{w} / \mathrm{c})$ ratio mix proportion from 0.30 to 0.40 . The density of the concrete controlled to $1500 \mathrm{~kg} / \mathrm{m}^{3}$ with the tolerance of $\pm 50 \mathrm{~kg} / \mathrm{m}^{3}$ as it is acceptable in accordance with the typical industrial practice in foamed concrete manufacturing [9]. The size of each trial mix sample is cube size of $100 \mathrm{~mm} \times 100 \mathrm{~mm} \times 100 \mathrm{~mm}$.

For splitting tensile strength, there are three different mix proportions with the PP of $0 \%, 0.25 \%$, and $0.40 \%$. Each proportion is tested for three different curing period which are 7 days, 28 days and 90 days. The size of each specimen is cylinder size of $200 \mathrm{~mm}$ height and $100 \mathrm{~mm}$ diameter.

\section{Mixing Procedure}

Lightweight foamed concrete was obtained initially by preparing the mortar as a base mix. The dry materials; OPC, sand and silica fume was mixed thoroughly. Next, an amount of water and SP added and mixed uniformly. This was followed by foam preparation and mixing of the foam to the mortar base. The foam was prepared by diluting the foaming agent with water and poured into the chamber of a locally fabricated foam generator. The stable foam was produced through the nozzle of the foam generator with a compressed air pressure of $0.50 \mathrm{MPa}$ consistently supplied to the foam generator. Prior to that, the density of mortar was determined to ensure the accurate amount foam needed to the mortar base to produce the targeted density. The flow table test was also done before the mixing of foam to the concrete.

The required amount of foam was then measured by weight and added into the base mix mortar. After the mix had blended uniformly, the foamed concrete was measured its bulk density by pouring the foamed concrete into the 1liter container (which equivalent to $1 \times 10^{-3} \mathrm{~m}^{3}$ ) and weight. The concrete mix was then poured into a mould with cube size of $100 \times 100 \times 100 \mathrm{~mm}$ for compressive test specimens.
The fresh lightweight foamed concrete was then left for 24 hours before de-moulding. The procedure was repeated for $0.25 \% \mathrm{PP}$ and $0.40 \% \mathrm{PP}$. The mixing procedure was repeated for splitting tensile strength.

\section{Testing method}

Flow table test was performed to the check the workability and consistency of the base mix mortar. Base mix with low water content will be too dry and causes the burst out of the bubble in foamed concrete and hence affecting the density and strength of the lightweight concrete. At the other hand, too much water would cause the concrete to segregate and causes the bubbles in the foamed concrete to move to the surface of the concrete. The flow table test is in accordance to ASTM C1437 [12]. The standard flow tests use a standard conical frustum shape of mortar with a diameter of four inches. This mortar sample was placed on a flow table and dropped 25 times within 15 seconds. As the mortar is dropped, it spread out on the flow table. The final diameters of the mortar sample were used to calculate the flow.

Inverted slump test was also conducted to determine the consistency of cement paste after the addition of foam. This test was conducted by using a slump cone and base plate, in accordance to ASTM C995 [13]. The slump was placed inverted and placed at the center of the base plate. The inverted slump cone is filled with fresh lightweight foamed. The cone was then lifted to $1 \mathrm{ft}$ height to allow the fresh concrete to flow to the base plate. The diameter of the slump was measured three times; the difference shall not be exceeding $50 \mathrm{~mm}$.

The compression test was conducted by using CYBERTRONIC Unit 109/159 Testing Machine. The test is in accordance to the ASTM C39 [14]. The axial loading was applied to the smooth area of the $100 \mathrm{~mm}$ cube until failure occurred. The cube was compressed with a constant loading rate of $0.2 \mathrm{kN} / \mathrm{s}$ until the specimen fails. The maximum load carried by the specimen were recorded. The compressive strength is calculated as the maximum load carried is divided by the cross-sectional area of the cube. Average compressive strength was obtained based on three cubic specimens (Fig. 1).

The procedure for splitting tensile test is same as in compressive test (Fig. 1). The difference is, the splitting tensile test is conducted on a cylinder with a diameter of 100 $\mathrm{mm}$ and height of $200 \mathrm{~mm}$ until the specimen fails. This test method consists of applying a diametric compressive force along the length of a cylindrical concrete specimen at a rate that it is within a prescribed range until failure occurs. The test was done in accordance with ASTM C496 [15].
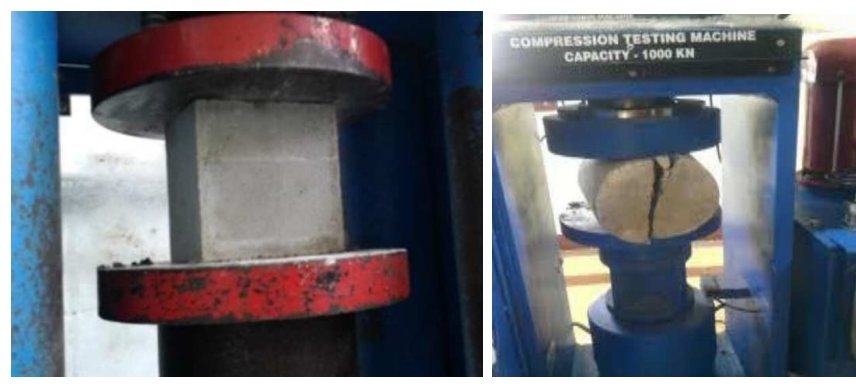

Fig. 1 Compression test (left) and splitting tensile test (right) 


\section{RESULTS AND DISCUSSION}

\section{A. Results of Trial Mix}

Table 1 shows the average flow table results for the trial mix. It can be seen that w/c ratio impacted the flow table measurement of each specimen. Higher w/c ratio would cause higher flow table measurement, indicating higher workability. However, in terms of consistency and cohesiveness of the concrete, too much water will reduce the cohesion of the concrete and causes separation of grout (segregation). Considering the characteristic of concrete, it was pointed out that concrete should not segregate and must be cohesive. Flow table with a measurement of $25 \mathrm{~cm}$ and above was considered too wet and tended to segregate. By observing the results, the addition of PP to the fresh concrete increased the average flow table measurement.

By looking at the data of each table, all samples have a flow table measurement of more than $25 \mathrm{~cm}$ at w/c ratio of 0.38 and 0.40 . Theoretically, samples with both ratios expected to segregate, therefore by using only the flow table values, it can be said that the concrete mixes were not suitable for foam concrete. Too much water will also cause the foam difficult to blend in with the mix.

TABLE I

Average Flow Table Measurement of Cube ConCRETE

\begin{tabular}{|c|c|c|c|}
\hline \multirow{2}{*}{$\begin{array}{c}\text { Water-cement } \\
\text { ratio (w/c) }\end{array}$} & \multicolumn{3}{|c|}{ Average flow table measurement (cm) } \\
\cline { 2 - 4 } & $\mathbf{0 \%} \mathbf{P P}$ & $\mathbf{0 . 2 5 \%} \mathbf{P P}$ & $\mathbf{0 . 4 \%} \mathbf{P P}$ \\
\hline 0.30 & 15 & 16 & 15 \\
\hline 0.32 & 18 & 19 & 18 \\
\hline 0.34 & 22 & 22 & 22 \\
\hline 0.36 & 24 & 24 & 24 \\
\hline 0.38 & $>25$ & $>25$ & $>25$ \\
\hline 0.40 & $>25$ & $>25$ & $>25$ \\
\hline
\end{tabular}

Table 2 shows the density of trial mix. The mortar density is the density of fresh concrete before mixing the foaming agent into the mix. This data is important to predict the amount of foam needed to reduce the fresh concrete density to $1500 \pm 50 \mathrm{~kg} / \mathrm{m} 3$ (density of LFC) while the average density of the cube was taken from three samples with dimension of $100 \mathrm{~mm} \times 100 \times 100 \mathrm{~mm} \times 100 \mathrm{~mm}$ when 7 days curing was applied to all specimens. The weights of all cubes are recorded before and after the curing to calculate the density of each specimen.

Based on a tabulation of the above results, few observations and explanations can be made. Firstly, the average density of the fresh foamed concrete is differed from with hardened average density. Most of the average weight increased after it was hardened. This is due to the loss of foam during mixing and placing the concrete mix into the mould. Secondly, the average density of cubes before and after the curing increases as the w/c ratio increase. This is due to the water absorption of foamed concrete during the curing process. The pore volume of the foam concrete increases the water absorption. The increment of the density of foam concrete after the curing is higher than the increment of normal concrete.
TABLE III

AVERAGE DENSITY OF LFC CUBES

\begin{tabular}{|c|c|c|c|c|c|c|}
\hline \multirow{2}{*}{$\begin{array}{c}\text { Water- } \\
\text { cement }\end{array}$} & \multicolumn{6}{|c|}{ Average density of cube $\mathbf{( k g / \mathbf { m } ^ { 3 } )}$} \\
\cline { 2 - 7 } $\begin{array}{c}\text { ratio } \\
\text { (w/c) }\end{array}$ & $\begin{array}{c}\mathbf{0 \%} \text { PP } \\
\text { Before } \\
\text { curing }\end{array}$ & $\begin{array}{c}\text { After } \\
\text { curing }\end{array}$ & $\begin{array}{c}\text { Before } \\
\text { curing }\end{array}$ & $\begin{array}{c}\text { After } \\
\text { curing }\end{array}$ & $\begin{array}{c}\text { Before } \\
\text { curing }\end{array}$ & $\begin{array}{c}\text { After } \\
\text { curing }\end{array}$ \\
\hline 0.30 & 1470 & 1535 & 1552 & 1562 & 1473 & 1530 \\
\hline 0.32 & 1541 & 1568 & 1573 & 1592 & 1490 & 1510 \\
\hline 0.34 & 1524 & 1553 & 1530 & 1539 & 1504 & 1525 \\
\hline 0.36 & 1527 & 1540 & 1478 & 1485 & 2124 & 2148 \\
\hline 0.38 & 1487 & 1580 & 1975 & 2014 & 2113 & 2138 \\
\hline 0.40 & 1676 & 1769 & 2273 & 2312 & 2102 & 2142 \\
\hline
\end{tabular}

Furthermore, by observing the result, there are huge increments of density in cube with w/c ratio of 0.38 and 0.40 for all samples as highlighted in each table. The densities of the samples are in the range of 1487 to $2312 \mathrm{~kg} / \mathrm{m}^{3}$. The first reason for this is because the high amount of water content is causing the concrete to bleed. The heavier particle such as cement paste settles and forces the excess mixing water upward. Also, the foam particles and the cement paste particles separated according to its weight and causing a two-layer separation as shown in Fig. 2. Due to this the weight of the hardened cubes concrete increases.

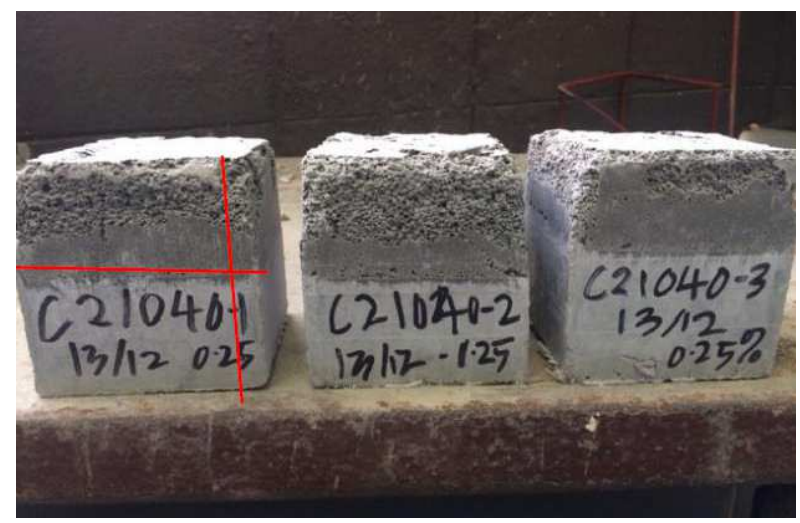

Fig. 2 Layers formed due to segregation

It was also being observed that the segregation layer of cubes with $0.40 \mathrm{w} / \mathrm{c}$ ratio is higher than the $0.38 \mathrm{w} / \mathrm{c}$ ratio. This shows that higher amount of water increases the level of segregation of the concrete.

The optimum water-cement (w/c) ratio of foamed concrete for a various percentage of PP is determined by comparing the compressive test result of each sample as depicted in Fig. 3. All the compressive test result plotted in a graph to see the optimum water-cement ratio of each mix. Water-cement ratio with the highest compressive test is usually taken as the optimum $\mathrm{w} / \mathrm{c}$ ratio.

By looking the results of $0 \% \mathrm{PP}$, the highest compressive strength is $16.93 \mathrm{MPa}$ with the w/c ratio of 0.38 . However, the flow table measurement of 0.38 and 0.40 water-cement ratio is more than $25 \mathrm{~cm}$ and segregated. Too much water content causes separation of the heavy and lighter particles in the concrete. Some bubbles moved to surface and burst out the mortar settled down. Furthermore, by comparing the density of each w/c ratio, cubes with 0.38 and 0.40 is exceeding the targeted density which is $1580 \mathrm{~kg} / \mathrm{m}^{3}$ and 
$1769 \mathrm{~kg} / \mathrm{m}^{3}$ respectively. Therefore, cube concrete with 0.38 and $0.40 \mathrm{w} / \mathrm{c}$ ratios are no longer considered as lightweight concrete. Therefore, the optimum w/c ratio of foamed concrete with $0 \% \mathrm{PP}$ is 0.36 .

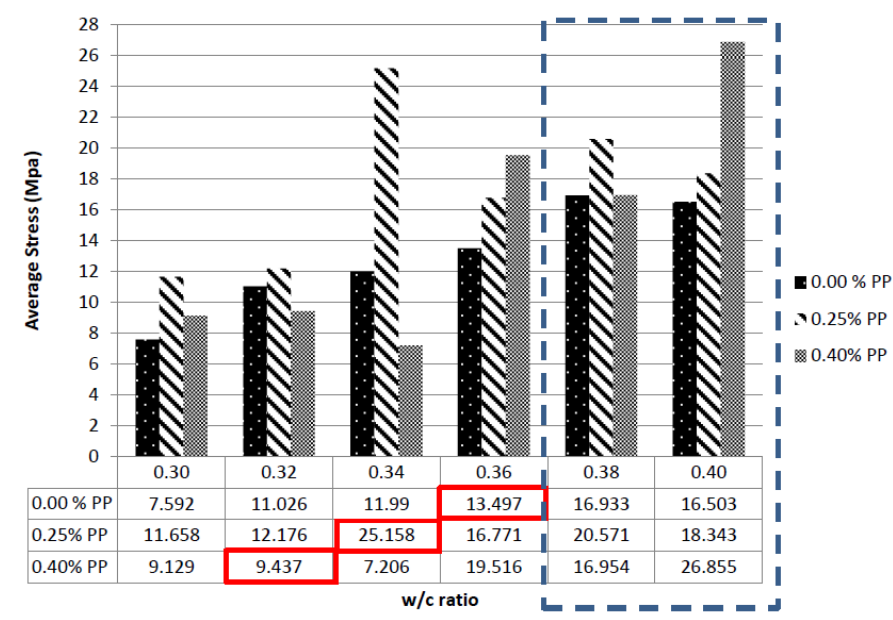

Fig. 3 Average compressive stresses vs. w/c ratio

The result of $0.25 \% \mathrm{PP}$ shows that the highest stress is $25.185 \mathrm{MPa}$ with the w/c ratio of 0.34 . Based on the density and flow table measurement result, cubes concrete with w/c ratio of 0.38 and 0.40 can no longer be considered as lightweight foamed concrete. Therefore, by considering the density and the compressive strength of the concrete, 0.34 with the compressive strength of $25.26 \mathrm{MPa}$ is taken as the optimum w/c ratio for foamed concrete with $0.25 \% \mathrm{PP}$.

It also can be observed that the compressive strength of the lightweight foamed concrete increase at $16.77 \mathrm{MPa}$ at $0.36 \mathrm{w} / \mathrm{c}$ ratio to $20.57 \mathrm{MPa}$ at $0.38 \mathrm{w} / \mathrm{c}$ ratio. This is because the lightweight foamed concrete with $0.38 \mathrm{w} / \mathrm{c}$ segregated and no longer acting as a foamed concrete but mortar concrete instead.

Fig. 4 shows the mode of failure of the segregated foamed concrete and normal foamed concrete. As shown in Fig. 4(a), the segregated layer break easily when compressive stress is applied to the cube while the failure mode of normal LFC (Fig.4(b)) is distributed uniformly.

Due to this, the compressive load is applied to the mortar surface, and only the mortar cross-sectional area was taken into account when calculating the compressive strength of the concrete. However, considering the characteristic of the lightweight foamed concrete itself, the cubes are no longer considered as a lightweight foamed concrete.

From the result of $0.40 \% \mathrm{PP}$, compression test of cubes with $0.40 \%$ PP. The highest average stress on the cube concrete is $26.86 \mathrm{MPa}$ with the w/c ratio of 0.40 . However, based on the result, the cube with $0.40 \%$ PP starts to segregate at $w / c$ ratio of 0.36 . As compression test applied, cubes with w/c ratios of $0.36,0.38$ and 0.40 resist the compression stress as a mortar with the strength range of 19.52 to $26.86 \mathrm{MPa}$.
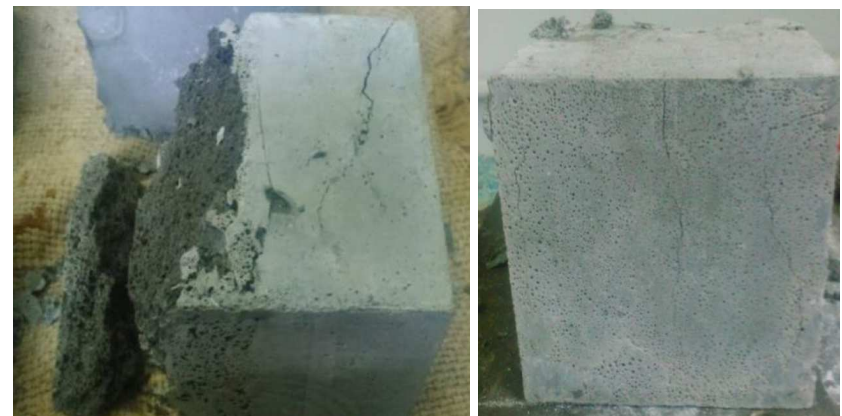

Fig. 4 Modes of failure (a) segregated LFC (b) normal LFC

Therefore, to obtain the optimum w/c ratio of the lightweight foamed concrete, only 0.30 to 0.34 is taken into consideration. The highest stress is $9.44 \mathrm{MPa}$ with w/c ratio of 0.32 . So, 0.32 is taken as the optimum w/c compared to the 9.13 MPa and 7.21 MPa value of compressive strength. The condition of hardened foamed concrete with a watercement ratio of 0.34 and 0.36 are shown in Fig. 5 .

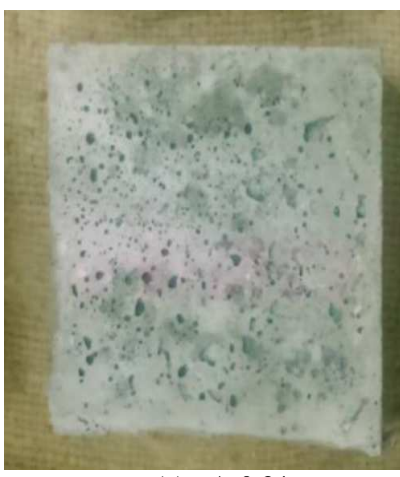

(a) w/c 0.34

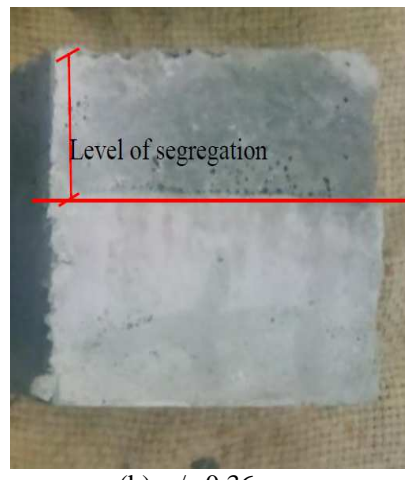

(b) w/c 0.36
Fig. 5 The hardened concrete condition

\section{B. Optimum Water-Cement Ratio}

The optimum water-cement (w/c) ratio obtained is plotted on a graph as shown in Fig. 6. The Figure shows the relationship between the optimum water-cement ratio and the percentage of PP in lightweight foamed concrete. Based on the graph, the optimum w/c ratio decreases as the percentage of PP increase. This result is compared with another trial mix with cement/sand ratio of 3:1. The comparison is shown in Fig. 7.

Based on the result, the optimum w/c ratio obtained with 3:1 cement-sand ratio is slightly lower than the optimum water-cement ratio of $2: 1$. This proves that the amount of solid ratio affects the amount of water needed in maximizing the compressive strength of the foamed concrete. As seen in the graph, the range of the optimum w/c ratio which is 0.32 to 0.36 . It also can be concluded that higher $\mathrm{c} / \mathrm{s}$ ratio needs lower w/c ratio to produce the maximum strength, at the same time providing a workable concrete mix. 


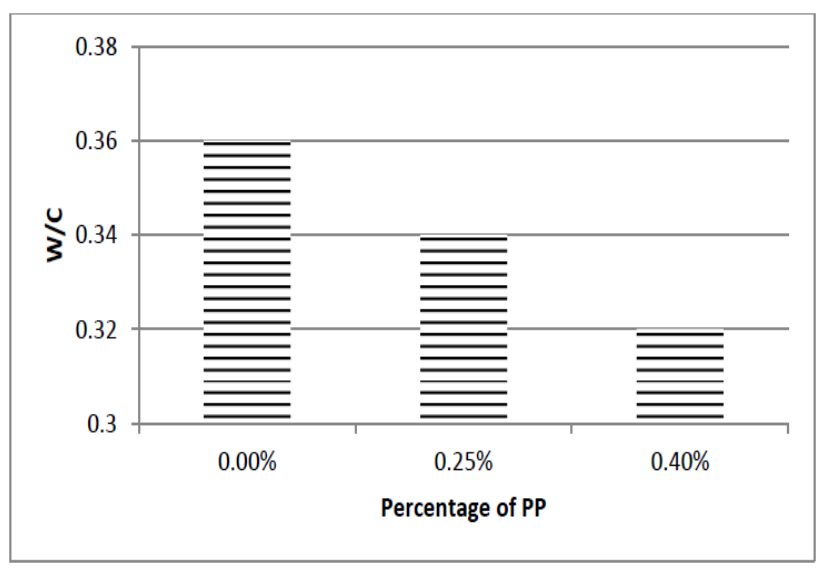

Fig. 6 Optimum w/c ratio vs. percentage of PP

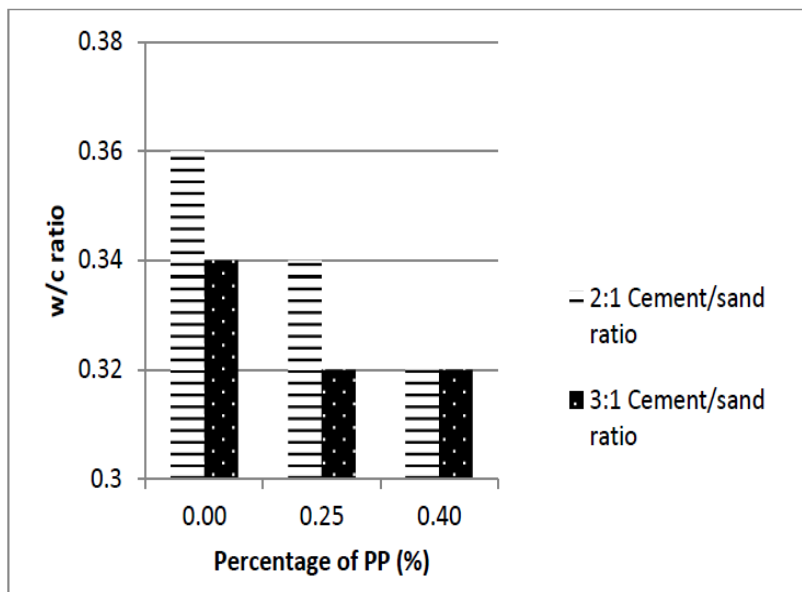

Fig. 7 Comparison of optimum w/c for LFC with 2:1 and 3:1 c/s ratio

\section{Splitting Tensile Result}

Table 3 show the result of the average density of cylinder foam concrete before and after curing. All the density of the specimens was controlled to $1500 \mathrm{~kg} / \mathrm{m}^{3}$. Based on the table shown, the density of cylinder concrete is increasing after several days of curing. It has also been observed that the increment in the average density of cylinder concrete is increasing as the period of curing increasing. This is because the concrete tends to absorb more water when it is immersed longer in water.

TABLE IIIII

AVERAGE DENSITY OF CYLINDER BEFORE AND AFTER CURING

\begin{tabular}{|c|c|c|c|c|c|c|}
\hline \multirow{2}{*}{$\begin{array}{c}\text { Amount } \\
\text { of PP }\end{array}$} & \multicolumn{6}{|c|}{ Average density of cylinder $\left(\mathbf{k g} / \mathbf{m}^{\mathbf{3}}\right)$} \\
\cline { 2 - 7 } & \multicolumn{2}{|c|}{$\mathbf{7 - d a y}$ curing } & \multicolumn{2}{|c|}{$\mathbf{2 8 - d a y}$ curing } & \multicolumn{2}{|c|}{$\mathbf{9 0 - d a y}$ curing } \\
\cline { 2 - 7 } & $\begin{array}{c}\text { Before } \\
\text { curing }\end{array}$ & $\begin{array}{c}\text { After } \\
\text { curing }\end{array}$ & $\begin{array}{c}\text { Before } \\
\text { curing }\end{array}$ & $\begin{array}{c}\text { After } \\
\text { curing }\end{array}$ & $\begin{array}{c}\text { Before } \\
\text { curing }\end{array}$ & $\begin{array}{c}\text { After } \\
\text { curing }\end{array}$ \\
\hline $0.00 \%$ & 1506 & 1549 & 1487 & 1593 & 1483 & 1602 \\
\hline $0.25 \%$ & 1494 & 1547 & 1492 & 1589 & 1489 & 1608 \\
\hline $0.40 \%$ & 1513 & 1547 & 1354 & 1422 & 1453 & 1576 \\
\hline
\end{tabular}

Table 4 shows the summary result of the average tensile stress of three different percentage of PP with 7 days, 28 days and 90 days curing age applied to 3:1 cement-sand ratio. Note that, the cement-sand ratio of $3: 1$ is taken based on the consideration of the amount of sand to the mix. Based on the result obtained, few observations can be made. Firstly, based on the average splitting tensile strength of the control sample which with $0.0 \% \mathrm{PP}$, the average stress of splitting tensile test is increasing as the period of curing increase. The average stress is increasing from 1.63 MPa to 7 days to 2.14 $\mathrm{MPa}$ at 90 days of curing. This simply shows that the curing period of the concrete does affect the tensile strength of the lightweight foamed concrete.

However, when the polypropylene fiber was added to the mix, there is a slight change compared to the usual pattern of lightweight foamed concrete without the addition of any polypropylene fiber. At a normal curing period (7 days) the result of splitting tensile test is increasing as the amount polypropylene fiber added increase. This shows that polypropylene fiber does enhance the tensile strength of the lightweight foamed concrete. The interfacial adhesion between the matrix of the concrete and fibers improved. The Higher amount of polypropylene fiber may be permits higher stress transfer. Thus, increases the tensile splitting strength of the foamed concrete. This pattern of the result is the same as with the pattern of a previous study [13] where the splitting tensile strength is increasing until at the addition of $1.5 \% \mathrm{PP}$.

TABLE IVV

Average Stressed From SPlitTing Tensile Test

\begin{tabular}{|c|c|c|c|}
\hline \multirow{2}{*}{$\begin{array}{c}\text { Amount of } \\
\text { PP }\end{array}$} & \multicolumn{3}{|c|}{ Average splitting tensile stress (MPa) } \\
\cline { 2 - 4 } & 7-day & 28-day & 90-day \\
\hline $0.00 \%$ & 1.613 & 1.935 & 2.138 \\
\hline $0.25 \%$ & 1.715 & 1.649 & 1.743 \\
\hline $0.40 \%$ & 1.815 & 0.991 & 1.647 \\
\hline
\end{tabular}

However, by comparing the average stress withstand by the lightweight foamed concrete with $0.25 \%$ PP and $0.40 \%$ PP for 28 days and 90 days, the stress is decreasing from $1.65 \mathrm{MPa}$ to $0.99 \mathrm{MPa}$ and 1.74 to $1.65 \mathrm{MPa}$ respectively. This is opposing to the result of 7 days curing. The possible reason is the characteristic of the foamed concrete which is porous. This is because the non-uniform distribution and orientation of PP cause some cracks in the concrete hence lowering the strength.

Next, by looking at the result of $0.40 \%$ PP at the curing of 28 days, the average stresses are the slightly off compared to other values. This may be because of the poor dispersion and orientation of PP fibers in the foamed concrete mixed that consequently increase the pore volume of cement matrix and creates more micro defects in cement matrix thus decreasing the tensile strength of the concrete. Another reason for $0.40 \%$ PP at 28 days to have a very low stress is due to the improper placing during the moulding process as was mentioned before. This can be seen with the changes of its density to a very low density during the hardening process, which changes from its controlled density $1500 \mathrm{~kg} / \mathrm{m}^{3}$ to $1354 \mathrm{~kg} / \mathrm{m}^{3}$.

\section{CONCLUSIONS}

From the data results discussion, several conclusions of the study are stated in order to answer the objectives of the study:

- The density achieved in this experiment is in the range of $1940 \mathrm{~kg} / \mathrm{m}^{3}$ to $1540 \mathrm{~kg} / \mathrm{m}^{3}$ with the achieved compression strength range 7.21 $\mathrm{MPa}$ to $25.16 \mathrm{MPa}$. 
- The optimum obtained from the compressive strength results with c/s ratio of $2: 1$ is $0.36,0.34$ and 0.32 for addition of polypropylene fiber of $0.00 \%, 0.25 \%$ and $0.40 \%$ respectively. For cement/sand ratio of $3: 1$, the optimum w/c is $0.34,0.32$ and 0.32 respectively. It can be concluded that the optimum $\mathrm{w} / \mathrm{c}$ ratio needed to achieve the maximum compressive strength is decreased as the amount of polypropylene fiber increases.

- The addition of polypropylene fiber enhances the tensile strength of the lightweight foamed concrete. By looking the result of splitting tensile strength for 7 days, the tensile strength increase from $1.61 \mathrm{MPa}$ to 1.82 MPa.

Overall, it can be concluded that polypropylene does enhance the tensile strength of the foamed concrete but not with significant increment. However, the split tensile strength results do not give the perfect estimation about the tensile strength of concrete because of the mixed stress field and fiber orientation. Although the result gives the good pattern about the mechanical strength of the material.

\section{ACKNOWLEDGMENT}

The authors would like to express their utmost gratitude to the technical and financial contribution by Malaysia Ministry of Higher Education (MOHE), Universiti Teknologi Malaysia (UTM), and Universitas Sriwijaya (UNSRI). Laboratory work assistance from Nur Nabila Farhana bt. Mohammad Fathilah, Raihana Farahiyah bt. Abdul Rahman and the lab technicians are also highly appreciated.

\section{REFERENCES}

[1] Neville, A. and Brooks, J. (2001). Concrete technology. Harlow, Essex, UK: Longman Scientific \& Technical.
[2] Nayak, N.V., \& Jain, A.K. (2012). Advanced concrete technology. Oxford: Alpha Science International Ltd., 28.1.

[3] Ramamurthy K., \& Kunhanandhan E. (2009). A classification of studies on properties of foam concrete. Cement \& Concrete Composites 31, pp. 388-396

[4] Brady K., Watts G. and Jones M.R. (2001) Specification for Foamed Concrete. Highways Agency and TRL Application Guide AG 39.

[5] Kearsley EP, Visagie M. (1999) Micro-properties of foamed concrete. In: Dhir RK \& Henderson N.A. (Eds). Specialist Techniques and Materials for Concrete Construction. UK: Thomas Telford.

[6] Valore RC. (1954) Cellular concrete part 1 composition and methods of production.ACI J;50:773-96

[7] Mindess, S. (2008). Developments in the formulation and reinforcement of concrete. Cambridge, England: Woodhead Pub.

[8] Hanizam Awang, M. H. (2014). Durability Properties of Foamed Concrete with fiber inclusion. World Academy of Science, Engineering and Technology International Journal of civil, Vol 8.

[9] Jones, M. and McCarthy, A. (2005). Preliminary views on the potential of foamed concrete as a structural material. Magazine of Concrete Research, 57(1), pp.21-31.

[10] Priti A. Patel, Dr. Atul K. D., \& Dr. Jatin A. Desai (2012). Evaluation of Engineering Properties for Polypropylene fiber Reinforced Concrete. International Journal of Advanced Engineering Technology, 3(1), pp. 42-45.

[11] Sadrmomtazi, A., Fasihi, A. and Haghi, A., (2008) Effect of Polypropylene Fiber on Mechanical and Physical Properties of Mortars Containing NANO-SIO ${ }_{2}$. In Proceedings of the Third International Conference on Concrete and Development pp. 11631172

[12] ASTM C1437-15, Standard Test Method for Flow of Hydraulic Cement Mortar, ASTM International, West Conshohocken, PA, 2015, www.astm.org

[13] ASTM C995-01, Standard Test Method for Time of Flow of FiberReinforced Concrete Through Inverted Slump Cone (Withdrawn 2008), ASTM International, West Conshohocken, PA, 2001, www.astm.org

[14] ASTM C39 / C39M-16, Standard Test Method for Compressive Strength of Cylindrical Concrete Specimens, ASTM International, West Conshohocken, PA, 2016, www.astm.org

[15] ASTM C496 / C496M - 11 Standard Test Method for Splitting Tensile Strength of Cylindrical Concrete Specimens. ASTM International, West Conshohocken, PA, 2016, www.astm.org. 